\title{
SEPARATION, DISPERSION, HUMIDIFICATION AND TRANSPORT OF FIBRES IN A PHYSICAL LUNG MODEL
}

\author{
Stoelinga, M.A., Marijnissen, J.C.M., Bibo, B.H. Prodi, V. \\ Delft University of Technology, Faculty of Chemical Engineering and Materials Science, \\ Particle Technology Group, P.O. Box 5054, 2600 GA Delft, The Netherlands.
}

\begin{abstract}
Due to the health hazards of asbestos fibres, industry is searching hard for safe fibrous substitutes. The question however remains if these new fibres endanger health not just as much. So it is important to investigate the relation between different fibre parameters and their health hazards. One of the first objectives is to gain information on the transport and deposition of fibres in the lung. For this purpose a physical lung model has been designed and built, simulating as much as possible the actual conditions in the human lung. For the experiments, well designed uniform fibres are highly desirable. To obtain these it was necessary to add an extra separation step with a large inertial spectrometer (LASPEC), designed by Prodi et al (1984), to the production process of the fibres. This production process was developed at the Delft University of Technology by Buwalda et al. (1990).

The dispersion of these fibres into the system proved to be possible with a spinning top aerosol generator (STAG). The lung model itself consists of glass tubes according to a model designed by Yeh and Schum (1980) with electric conducting inner coating. A newly designed humidification system creates a near saturated atmosphere in the lung model.
\end{abstract}

\section{Keywords}

Fibre separation; monodisperse fibres; fibre dispersion; fibre deposition; fibre transport; lung model.

\section{Introduction}

Industry has been searching hard for fibrous material that has no negative health effects as replacement for asbestos fibres. The question remains however if these fibres prove not to be equally dangerous. So it is important to investigate the relation between different fibre parameters and their health hazards. One of the first objectives is to gain information on the transport and deposition of fibres in the lung. For this purpose a physical lung model has been designed and built, simulating as much as possible the actual conditions in the human lung. This model is an adaptation of the model presented by Marijnissen et al (1991). In fig. 1 a schematic drawing of the system is shown. The fibres used in this system are nylon fibres that are precisely cut according to length with a microtome and further separated on diameter with sedimentation. However, these, by the authors produced fibres, were regarded as not sufficiently uniform and an extra separation step was considered necessary. Those fibres, with lengths around $30 \mu \mathrm{m}$ and diameters varying between 0.5 and $2 \mu \mathrm{m}$, were further separated with a large inertial spectrometer (LASPEC). To disperse those uniform fibres in the air some experiments with a spinning top aerosol generator, a dry powder disperser and a DeVilbis nebulizer were done.

\section{Humidification}

The humidification of the air is further optimized by using a special humidifier. This humidifier consists of a 
reservoir with a long spirally formed outlet, surrounded by a temperature bath. This way it is possible to saturate clean air at an elevated temperature by guiding it through the reservoir that is filled with water. Droplets formed in the process are intercepted by the coils in the outlet before this stream enters the main airstream. Since the main airstream, with the fibres in it is at a lower temperature the result is a highly humidified airstream.

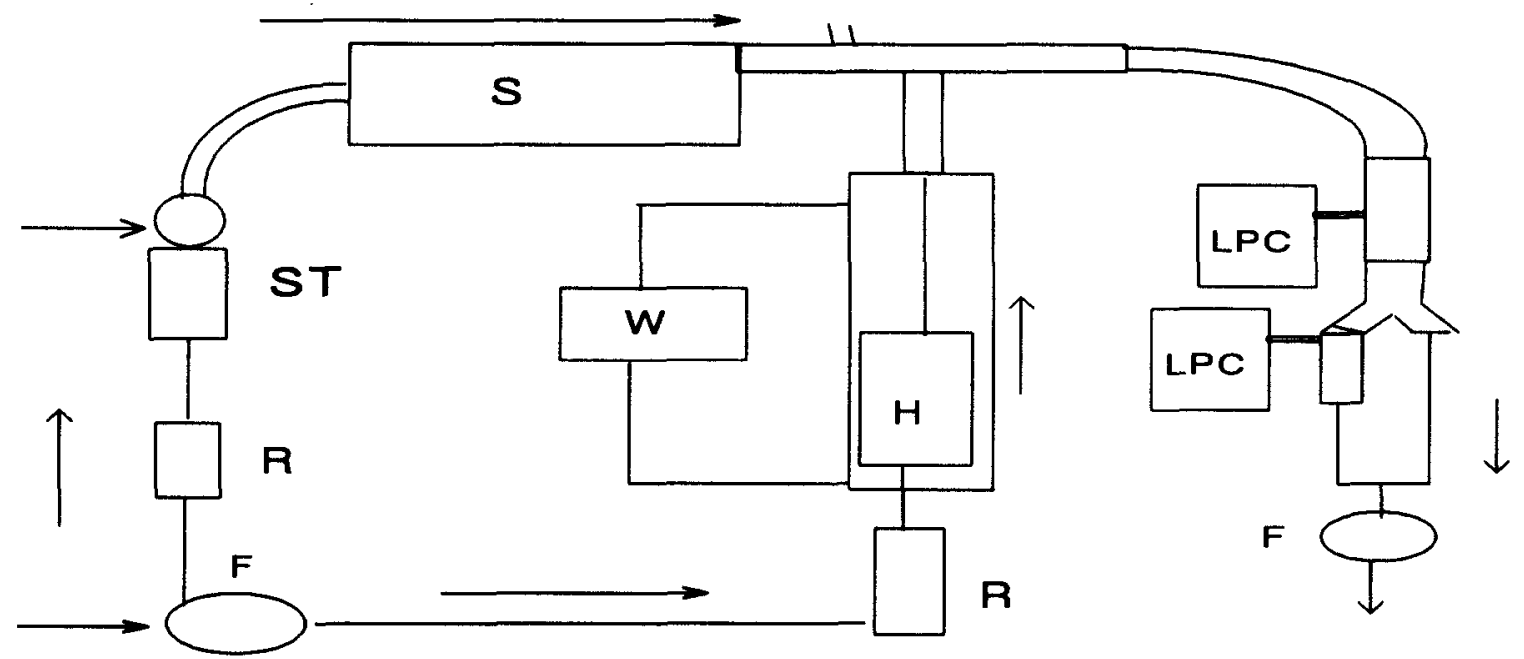

fig 1. Diagram of the system build to research transport and deposition in a physical lung model. $F=$ filter, $\mathbf{R}=$ rotameter, $\mathbf{S T}=$ spinning top aerosol generator, $\mathbf{S}=$ Krypton source, $\mathrm{W}=$ heating bath, $\mathbf{H}=$ humidifier, LPC $=$ laser particle counter.

\section{Separation with the LASPEC}

A class of instruments based on inertial separation was developed by Prodi. Three designs were made according to the same principle. The theory is described by Prodi et al (1988). The device used to separate the fibres for the lung deposition experiments was the large inertial spectrometer (LASPEC). In fig. 2 the apparatus is depicted.

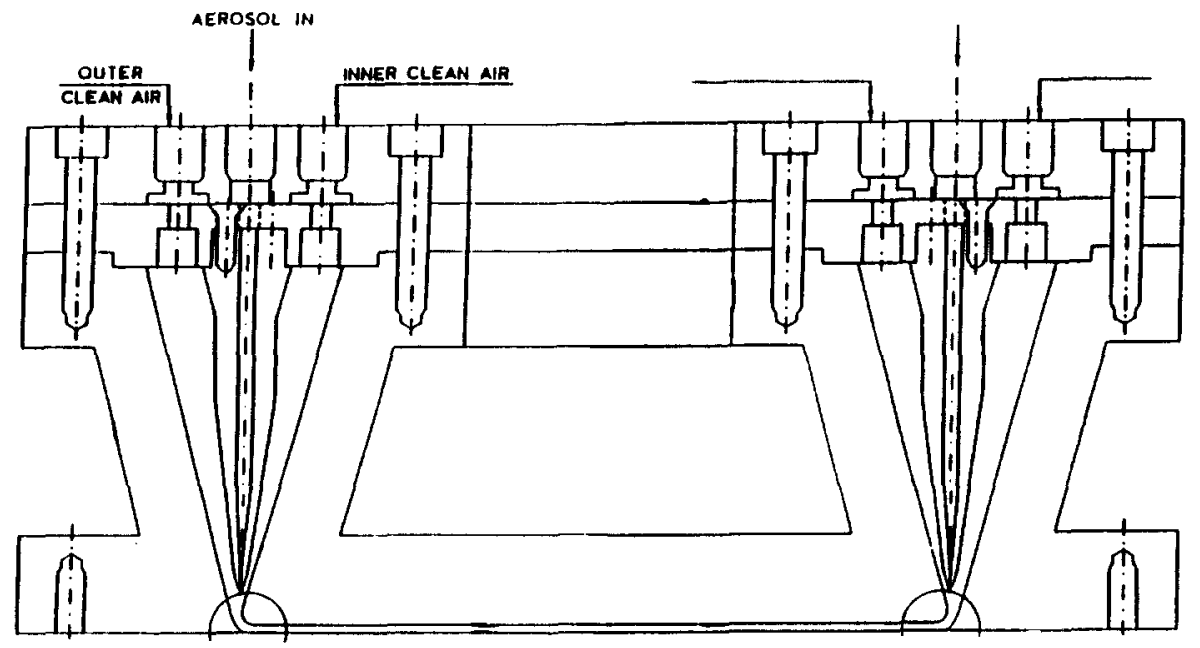

fig 2. Cross section of the separation section of the LASPEC.

The fibres in an airstream are lead around a bend with clean sheath air through a small slit. Due to their inertia they deposit on the filter that is placed behind the bend. Since all the air has to pass through the filter impaction 
is not the only mechanism that governs the deposition. By varying the speeds of both clean airstreams the deposition pattern can be changed. Fibres were added to one of inertial spectrometers for analytical purposes before (Prodi et al (1982)), but it was not yet tried to separate fibres with the LASPEC.

The experiments with the LASPEC were done while spraying the described fibres, dispersed in alcohol, with a DeVilbis nebulizer at a rate of $5 \mathrm{lpm}$. The outer sheath air flow was $65 \mathrm{lpm}$ while the inner sheath air flow was $16 \mathrm{lpm}$. The alcohol was evaporated. Most of the fibres deposited around $40 \mathrm{~mm}$ from the centre of the filter. A large production was not yet obtained due to difficulties dispersing the fibres using a nebulizer and the collection method in the LASPEC. In fig. 3 four pictures are shown with samples taken from the filter on different distances from the centre.
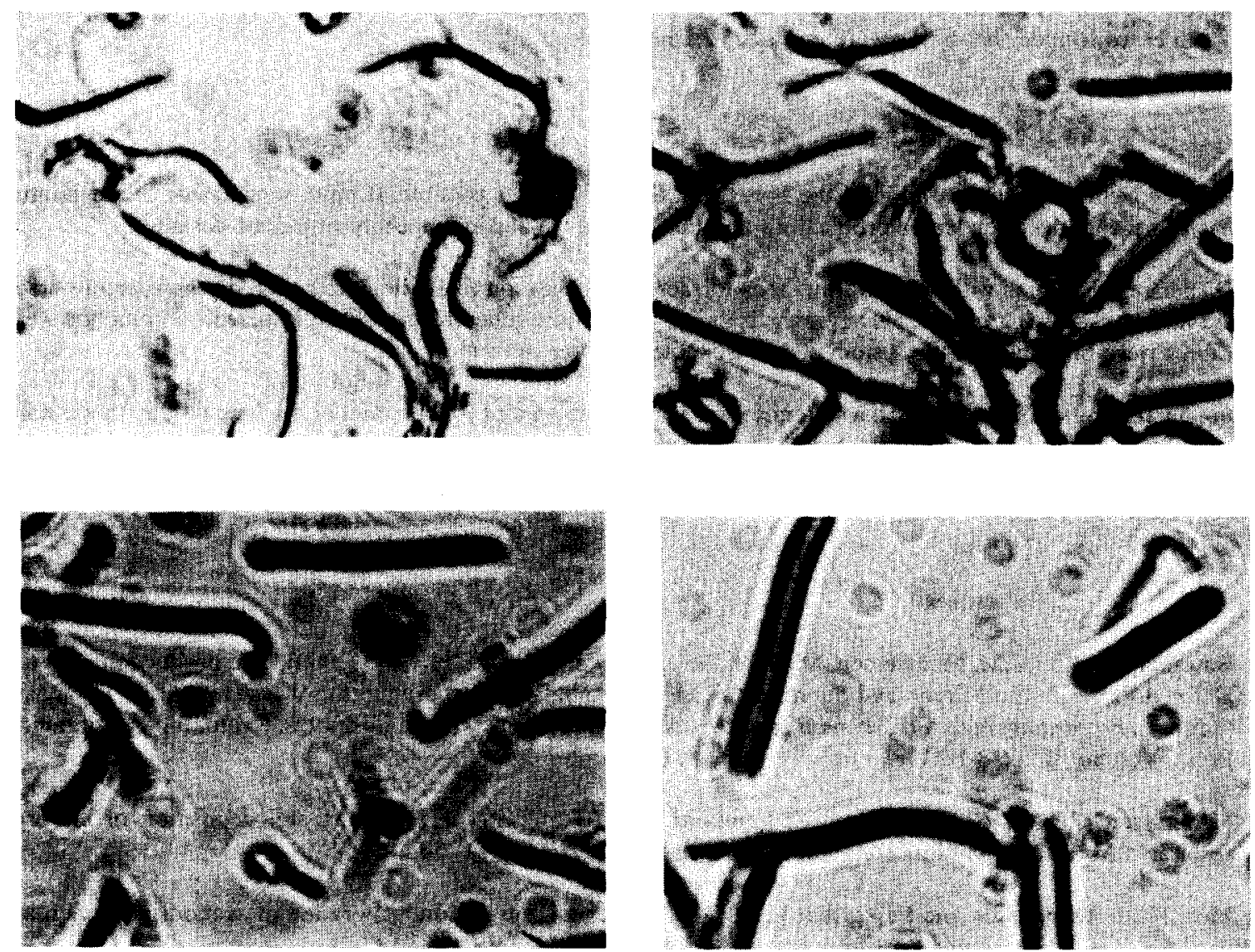

fig 3. Pictures of the fibres deposited on the filter of the LASPEC taken $2 \mathrm{~mm}$ apart, starting close to the centre of the filter moving away from it. ( $1 \mathrm{~cm}$ is about $10 \mu \mathrm{m}$ )

It can be seen that separation occurred but that the fibres are not stretched out over large distances. Different settings of the apparatus may enlarge these distances. Some alignment with the direction of the flow can be seen. It could be that the fibres align themselves with the direction of the flow during their flight as stated by Prodi et al (1982). But it is also possible that alignment occurs when part of the fibre touches the filter while the other part is still in the main stream. This way the fibre is forced in the direction of the flow because one point of the fibre has already contact with the filter.

\section{Dispersion of fibres in the air}

Dispersing fibres in the air with a nebulizer (DeVilbis) can cause clogging and impaction in the bend. It is also difficult to obtain a constant concentration of fibres in the air. Another method that can be used is a dry powder 
disperser that was developed in Delft, namely the Van der Wel aerosol generator (WAG). For this method fibres have to be blown out of a fluid bed of fibres and glass beads. It did not function since the fibres stuck to the glass beads. Finally it was tried to disperse the fibres with an apparatus not originally designed for this purpose, the spinning top aerosol generator (STAG).

A fluid with fibres suspended in it is brought upon a fast spinning rotor with a needle. A thin film forms over the rotor and is forced, due to the centrifugal forces, to the side of the rotor where the fluid is broken up in particles of two sizes, Mori et al (1990). Those droplets, with fibres in them, can than be lead through the system were the fluid is evaporated from the fibre. Slight alterations to the original apparatus proved to be very helpful. Accurate positioning of the needle both in vertical and horizontal direction was made possible.

Some experiments done with a set up as in fig. 1 resulted in dispersed fibres at the end of the system. Fibres were seen under the microscope when a sample was taken from the system after the Krypton source. This way it can be concluded that fibres were entrained in the droplets.

\section{Conclusions}

It was concluded that separation of the fibres with the LASPEC is possible. It must be said that the apparatus has to be optimized for larger productions and that a better collecting mechanism can be designed.

Dispersing the fibres with standard methods for aerosol generation like a nebulizer or a dry powder disperser did not give satisfying results. However the spinning top aerosol generator as a fibre disperser did function well. Fibres were brought into the system at a reasonable constant concentration.

Finally the work done resulted in a system for measurements on a physical model of the human lung that is easy to operate. It does simulate the natural conditions in the human lung. There is good humidification while the fibres can be dispersed in air at a constant rate. The fibres used are monodisperse so that future calculations and modelling can be simplified.

\section{References}

Buwalda, J.R.F., J.C.M. Marijnissen, M. Bilius, S.M. Lemkowitz and B.H. Bibo (1990). The production of WellDefined Fibres in the Micron and Submicron Range for Inhalation Experiments. S. Masuda and K. Takahashi (editors). Proceedings of the 3rd Intemational Aerosol Conference, 24-27 September 1990, Kyoto, Japan, Pergamon Press, Volume II, 1238-1241.

Marijnissen, J.C.M., A. Zeckendorf, S. Lemkowitz, H. Bibo (1991)., Transport and deposition of uniform respirable fibres in a physical lung model. J. Aerosol Sci. 22 (suppl. 1) S859-S862.

Mori H., J. Marijnissen and B. Scarlett (1990) Optimal conditions for the generation of monodisperse aerosol particles using the spinning top generator. J. Aerosol Sci. 21 (suppl. 1) S661-S664.

Prodi, V., F. Belosi and A. Mularoni (1984). A high flow inertial spectrometer. Aerosols, Liu, Pui, Fissan (editors).

Prodi, V., F. Belosi, A. Mularoni and P. Lucialli (1988). PERSPEC: A personal sampler with size characterization capabilities. Am. Ind. Hyg. Assoc. J. 49 75-80.

Prodi, V., T. Zaiacomo, D. Hochrainer and K. Spurny (1982). Fibre collection and measurement with the inertial spectrometer. J. Aerosol Sci. $\underline{13}$, 49-58.

Yeh, H.C. and G.M. Schum (1980). Models of human lung airways and their application to inhaled particle deposition. Bull. Math. Biol., 42, 461-480. 